\title{
Prion theory: Induction of Prion Diseases by Nanoparticles Conversion (Prpc To Prpsc) Related to Electromagnetic Field
}

\author{
Amel Hanini ${ }^{1}$, Ahmed Rjeb ${ }^{2}$ and Hafedh Abdelmelek ${ }^{1 *}$ \\ ${ }^{1}$ Laboratoire de Physiologie Intégrée, Carthage University, Tunisia \\ ${ }^{2}$ Laboratoire d'Anatomie Pathologique, École Nationale de Médecine vétérinaire de Sidi-Thabet, Université de
}

Submission: August 14, 2017; Published: August 30, 2017

*Corresponding author: Pr Hafedh Abdelmelek, Carthage University, Faculté des Sciences de Bizerte 7021 Jarzouna, Tunisia, Fax: (216) 72590 566/ (216) 93006057; Email: hafedh.abdelmelek@fsb.rnu.com/ habdelmelek@yahoo.com

\begin{abstract}
Prion theory point to a mechanism of toxicity related to the conversion of Coated (PrPc) nanoparticles (NPs) to uncoated (PrPsc) NPs under electromagnetic field could help scientific community to better understand prion diseases. However, research using nanosciences associated to electromagnetic field exposure of coated $(\mathrm{PrPc}) \mathrm{NPs}$ and its conversion to uncoated NPs (PrPsc) triggering membrane receptors of the nervous system is poorly understood. Protein (PrPc) activated or influenced by uncoated NPs (PrPsc) under electromagnetic field could enhance protein 3D conversion; leading to prion diseases. The present prion theory gives the scientific community a novel approach. Interestingly, magnetic field-enhanced nano-protein to do a pathological folding, can generate large numbers of uncoated protein (PrPsc) and has scientific relevant applications for adoptive neurology.
\end{abstract}

\section{Introduction}

Until now in the field of neurobiology and medicine, prion diseases can be considered as a mystery to their unusal mechanism of pathogenicity. Take anything you learned in the field of neurobiology, especially about genetics of nervous system diseases and throw it out the door because prion diseases are exceptional and probably the only pathology without genetic support and clear mechanism. Incredibly, when we begin to understand the prion diseases in order to explain Mad Cow disease and other related diseases, conversion from 3D protein PrPc to PrPc remained unclear until now [1]. In the field of zoonosis or other diseases, the screening of pathogens give us quick results, they are not a bacteria, not a fungi, not a virus, but a protein called prion. The theory that a protein can propagate and induce disease has become a lightning-rod for controversy and has made the prion hypothesis one of the most hotly contested issues in molecular neurobiology for all these considerations we propose a new theory based on nanosciences and the bioeffects of electromagnetic field that could explain in part the folding or misfolding of many proteins. The prion theory of disease was developed in order to explain the old nomenclature of prion diseases (Transmissible Spongiform Encephalopathies (TSEs)), a group of fatal diseases that overwhelm neural cells and riddle the brain with sponge-like holes. TSEs have been found in various species, including sheep, cows, elk and human beings. The disease, appropriately named scrapies, was devastating, often requiring the sacrifice of entire herds. Human variants of TSEs are extremely rare, limited mainly to a neurodegenerative disease called Kuru found in cannibalistic Pacific Islanders, and Creutzfeldt-Jakob Disease (CJD), a disorder diagnosed in one person per million. Both these diseases share common symptoms, including gait disorders, jerky movements, and dementia that lead to death months after the first appearance of symptoms [2-4]. When Prusiner obtained a pure sample of infectious material, he began working to identify the disease causing agent. Prusiner added enzymes that destroyed DNA and RNA, he found no change in infectivity. Adding proteinneutralizing enzymes to this cocktail, however, caused a sharp drop in infectivity. This observation set the stage for a theory of disease transmission that Prusiner admitted was "heretical" when he suggested it. In a 1982 Science paper, Prusiner [2] introduced the world to the idea of a proteinaceous infectious particle-or "prion" as he dubbed it. The complete nature of the theory remains unknown and some of the fundamental issues are unresolved [2].

Researchers believe that at the heart of TSEs is the conversion of a particular protein (known as the Prion-related Protein, or 
PrP) from a normal (PrPc) to an abnormal, "scrapie-cell" (PrPsc), shape. Both forms of the protein consist of the same building blocks but different final products - just like the Transformers toys that could assume two shapes, one benign and the other aggressive. In the prion theory of disease, a PrPsc recruits and re-shapes a PrPc to match its own form. As more cells die of infection, they leave behind the spongy, holey brain that is a hallmark of TSEs. The present mini-review discusses a new theory based on the concept of induction of prion diseases by a simple conversion from coated nanoparticles which is a normal form of protein (PrPc) to an abnormal form which is the uncoated nanoparticles (PrPsc). It is important to mention that the PrPc or PrPsc sizes can be considered as nanoparticles in reference to nanosciences definitions. In nanosciences the uncoated nanoparticles agglomerate with chemical and physical laws as show previously in different studies [5,6]. Moreover, toxic effects of uncoated (PrPsc) nanoparticles in different nervous system animal species were well discussed by different researchers related to the increase of relativities of the particles with different compounds of the nervous system. Human and animal brains were exposed to different concentrations of uncoated (PrPsc) nanoparticles and contain naturally in its structure coated (PrPc) nanoparticles probably inducing and inversion of PrP ratio $=$ PrPsc/PrPc. In physiological environment the PrP ratio is equal to zero. Following the generation of the uncoated NPs the ratio increase and reach high values. In exposures to coated-NPs, particles induced lower cytotoxicity than uncoated particles. Analysis showed that uncoated NPs were more cytotoxic to the nervous system. Changes in sub-cellular architecture were observed with uncoated (PrPsc). Moreover, while uncoatedNPs resulted in decreased quality and functionality of nervous system. In nowadays, the complete nature of the prion theory remains unknown as far as we know and some of the fundamental issues are unresolved. The real question is by any mechanism we have the conversion of PrPc to PrPsc probably by different agents like electromagnetic field, pesticides, heavy metals, and other xenobiotics. Both forms of the protein coated nanoparticles (PrPc) to uncoated nanoparticles (PrPsc) consist of the same building blocks but different final products - just like the Transformers toys that could assume two shapes, one benign and the other aggressive.

\section{Nanoparticle Theory of Prpc}

Coated and uncoated nanoparticles, like other nano-sized particles, exhibit special properties relative to their bulk counterparts partly due to their very small size and greater surface area. As a consequence of production of different types of nps as a ratio=nps (prpsc)/nps (prpc) which the pathogen form can be considered as uncoated nps (prpsc). new applications under development, rigorous knowledge are needed about the potential impacts of these pathogen nps (prpsc) on human and/ or animals. Over the past decade, research on biological effects of various np types (prpsc) \& nps (prpc) has been performed on various cell lines, and animal models. in vitro toxicity studies have indicated effects of np types (prpsc) \& nps (prpc) on neuron cells. in vivo, exposures of nps (prpsc) have shown toxic effects in various mammalian models. Moreover, studies in rats and mice have demonstrated toxicity of nps in a variety of target of the human and animal brains. from these in vitro and in vivo studies, the proposed mechanisms of coated and uncoated nps-induced toxicity are the increase of reactivity of the uncoated nps with the nervous system related to their high specific surface. even though, there is growing evidence that uncoated nps (prpsc) are toxic in various test models, the exact mechanisms of uncoated nps toxicity remain unclear. Toxicological studies of nps (prpsc) have demonstrated that physicochemical properties of nps including size, shape, surface coating, surface charge, solubility, and chemical composition could dramatically affect nps behaviour in biological systems and thus influence the toxicity of nps in the nervous system of different animal models. A number of studies reported that uncoated nps (prpsc) toxicity was dependent on their size and surface. Similarly to other nps, the size of uncoated nps probably is linked to cellular uptake processes in the brain. The surface has been shown to affect the affinity of nps for the neuron cell surface and the dissolution or the release of compounds from uncoated nps, which could explain the toxicity mechanism of uncoated nps (prpsc) compared to coated nps (prpc). the investigation of the physicochemical characteristics and their impact on the biological effects of uncoated nps is important for the better understanding of neurotoxic mechanism. the study provides scientific insight relating physical/chemical characteristics of uncoated nps to cell damage and possible toxicity mechanisms of these nps in the central nervous system [5-7].

\section{Electromagnetic Field Theory of PrPc}

Many animals can sense the geomagnetic field, which appears to aid in behaviours such as migration. The influence of man-made electromagnetic fields (EMF) on biology, however, is potentially more sinister, with adverse health effects being claimed from exposure to fields from earth magnetic field, mobile phones or high voltage power lines. Do these phenomena have a common, biophysical origin, and is it even plausible that such weak fields can profoundly cause bioeffects of EMF especially on free radicals and oxidative stress associated to a positive modulation or negative modulation of protein folding or misfolding [8].

Radical pair intermediates are widespread in protein reaction mechanisms, and the radical pair mechanism has risen to prominence as perhaps the most plausible means by which even very weak fields might impact biology [5,9] especially coated nps (prpc) to convert them to uncoated nps (prpsc) without any genetic mechanism. In this new views mini-review, we will discuss the literature that has investigated the topic of magnetic field effects in proteins and the implication of the size/shape of the nps on the pathogencity of prion diseases in the nervous system. The lack of complete mechanism related to prion diseases encourages us to propose a new view and 
theory related to these exceptional diseases. Electromagnetic field and spin effects have proven to be useful mechanistic tools for radical mechanism and protein folding-misfolding model in neurobiology. Magnetic fields can influence the course of chemical reactions on coated nps to transform them on uncoated nps via different mechanism using nanosciences laws. Despite growing anxiety about the possibly damaging effects of nonionizing electromagnetic radiation on living tissue especially nervous system very little attention has been devoted to the investigation of magnetic field effects on biological systems especially protein like prpc. The proposed research will investigate uncoated nps reactions in neuron cells under the influence of magnetic fields with a particular focus on the effects of magnetic fields on the conversion from coated to uncoated nps and the behaviour of uncoated nps near neurons or glial cells [10]. Additionally, prompted by theoretical predictions, the protein folding-misfolding depend on magnetic field effects directly or indirectly via free radicals to generate prion diseases [11].

\section{Conclusion}

The prion theory based on nanosciences and electromagnetic bioeffects on protein folding give the scientific community an innovative research approach that enhanced nano-protein to do a pathological folding or misfolding implicated in the generation of large numbers of uncoated protein (PrPsc) leading to prion diseases.

\section{Referances}

1. Aguzzi A, Polymenidou M (2004) Mammalian prion biology: one century of evolving concepts. Cell. 116(2): 313-327.
2. Prusiner SB (1982) Novel proteinaceous infectious particles cause scrapie. Science 216(4542): 136-144.

3. Johnston $N$ (2004) Clearing hurdles: prions know how to do it. The Scientist 18(11): 18.

4. Legname G, Baskakov IV, Nguyen HB, Riesner D, Cohen FE, et al. (2004). Synthetic Mammalian Prions. Science. 7(305): 673-676.

5. Ferchichi S, Trabelsi H, Azzouz I, Hanini A, Rejeb A, et al. (2016) Evaluation of oxidative response and tissular damage in rat lungs exposed to silica-coated gold nanoparticles under static magnetic fields. Int J Nanomedicine 11: 2711-2719.

6. Hanini A, Schmitt A, Kacem K, Chau F, Ammar S, et al. (2011) Evaluation of iron oxide nanoparticle biocompatibility. Int J Nanomedicine 6: 787794.

7. Baratli $Y$, Charles AL, Wolff V, Ben Tahar L, Smiri L, et al. (2013) Impact of iron oxide nanoparticles on brain, heart, lung, liver and kidneys mitochondrial respiratory chain complexes activities and coupling. Toxicol in vitro 27(8): 2142-2148.

8. Borgia A, Kemplen KR, Borgia MB, Soranno A, Shammas S, et al. (2015) Transient misfolding dominates multidomain protein folding. Nat commun 17(6): 8861.

9. Maaroufi K, Had-Aissouni L, Melon C, Sakly M, Abdelmelek H, Poucet B, Save E (2014) Spatial learning, monoamines and oxidative stress in rats exposed to $900 \mathrm{MHz}$ electromagnetic field in combination with iron overload. Behav Brain Res 258: 80-89.

10. Banaceur S, Banasr S, Sakly M, Abdelmelek H (2013) Whole body exposure to $2.4 \mathrm{GHz}$ WIFI signals: effects on cognitive impairment in adult triple transgenic mouse models of Alzheimer's disease (3xTg-AD). Behav Brain Res 240: 197-201.

11. Elferchichi M, Maaroufi K, Ammari M, Sakly M, Abdelmelek H (2015) Effects of combined ferrous sulfate administration and exposure to static magnetic field on brain oxidative stress and emotional behavior. Arch Ital Biol 153(1): 37-45.

\begin{tabular}{|l|}
\hline \multicolumn{1}{|c|}{ Your next submission with Juniper Publishers } \\
will reach you the below assets \\
- Quality Editorial service \\
- Swift Peer Review \\
- Reprints availability \\
- E-prints Service \\
- Manuscript Podcast for convenient understanding \\
- Global attainment for your research \\
- Manuscript accessibility in different formats \\
( Pdf, E-pub, Full Text, Audio) \\
- Unceasing customer service \\
Track the below URL for one-step submission \\
https://juniperpublishers.com/online-submission.php
\end{tabular}

